\title{
Peptide-Controlled Assembly of Macroscopic Calcium Oxalate Nanosheets
}

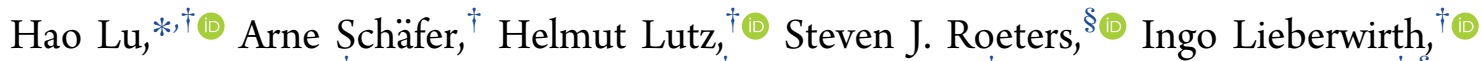 \\ Rafael Muñoz-Espí, ${ }^{\ddagger}{ }^{\ddagger}$ Matthew A. Hood, ${ }^{\dagger}$ Mischa Bonn, ${ }^{\dagger}$ a and Tobias Weidner ${ }^{\dagger, \S_{(0)}}$ \\ ${ }^{\dagger}$ Max Planck Institute for Polymer Research, Ackermannweg 10, 55128 Mainz, Germany \\ ${ }^{\ddagger}$ Institute of Materials Science (ICMUV), Universitat de València, C/Catedràtic José Beltrán 2, 46980 Paterna, Spain \\ ${ }^{\S}$ Department of Chemistry, Aarhus University, Langelandsgade 140, 8000 Aarhus C, Denmark
}

\section{Supporting Information}

\begin{abstract}
The fabrication of two-dimensional (2D) biomineral nanosheets is of high interest owing to their promise for applications in electronics, filtration, catalysis, and chemical sensing. Using a facile approach inspired by biomineralization in nature, we fabricate laterally macroscopic calcium oxalate nanosheets using $\beta$-folded peptides. The template peptides are composed of repetitive glutamic acid and leucine amino acids, selforganized at the air-water interface. Surface-specific sum frequency generation spectroscopy and molecular dynamics simulations reveal that the formation of oxalate nanosheets relies on the peptide $-\mathrm{Ca}^{2+}$ ion interaction at the interface, which not only restructures the peptides but also templates $\mathrm{Ca}^{2+}$ ions into a calcium oxalate dihydrate lattice. Combined, this enables the formation of a critical structural intermediate in the assembly pathway toward the oxalate sheet formation. These insights into peptide-ion interfacial interaction are important for designing novel inorganic $2 \mathrm{D}$ materials.
\end{abstract}

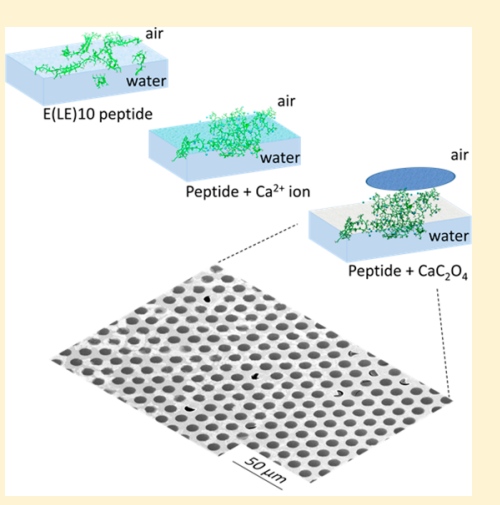

$\mathrm{T}$ he design and synthesis of $2 \mathrm{D}$ nanomaterials have opened up a new field of ultrathin, functional materials with atomic precision. ${ }^{1}$ Organic sheet materials such as graphene have received much attention recently. Inorganic $2 \mathrm{D}$ nanomaterials composed of metal oxides, ceramics, and minerals also hold great promise as materials with new physical and chemical properties, which can be chemically tuned and self-assembled using effective, low-cost, bottom-up fabrication methods. ${ }^{2}$ Synthesized from relatively cheap building blocks, such materials offer great flexibility in tailoring surface morphology, porosity, chemical functionality, and electronic properties. One particularly interesting strategy to obtain functional 2D inorganic materials has been their templated assembly via organic precursor structures. Here, the chemical and polymorph structure can be encoded in the chemistry and structure of the organic templating layer. Nature uses this mechanism with proteins, which "engineer" intricately mineralized tissue by steering the growth of minerals and thereby achieving polymorph and shape control in, e.g., bone and teeth ${ }^{3}$ and exoskeletons of mollusks or diatoms. ${ }^{4}$ Over the past years, researchers have therefore been taking clues from Nature in an attempt to mimic the control that specialized biomolecules involved in hard tissue biogenesis exert over the formation of inorganic layered materials. Despite the great efforts, biomimetic fabrication of $2 \mathrm{D}$ inorganic materials still largely relies on trial and error and, therefore, typically requires substantial investments of time and funds.

Surfactants, ${ }^{5}$ lipids, ${ }^{6}$ peptoids, ${ }^{7,8}$ and polymers ${ }^{9}$ have been reported to grow $2 \mathrm{D}$ organic sheets. Such structures can potentially steer the growth of biomimetic mineral nanosheets at interfaces, such as the air-water ${ }^{10}$ or oil-water interfaces, ${ }^{8}$ into desired polymorphs and morphologies. Solid-supported layers have also been used for the synthesis of layered materials. ${ }^{1}$ Oxide and ceramic materials are particularly interesting in this context for the assembly of electronic circuitry, semiconductors, photonic materials, as well as nanometer thin membranes for desalination, filtration, chemical separation, catalytic applications, and sensors. For biomedical or nanofabrication applications, biomineral nanosheets have been explored recently. ${ }^{2,10,11}$ In particular, calcium carbonate and calcium oxalate $\left(\mathrm{CaC}_{2} \mathrm{O}_{4}\right)$ are versatile biocompatible materials, which are chemically and structurally extremely stable.

The synthesis of extended calcium carbonate sheets using biomolecules as organic templates has recently been reported. ${ }^{10}$ In contrast, $\mathrm{CaC}_{2} \mathrm{O}_{4}$, the dominant part of kidney stones $^{12,13}$ and notoriously stable, has largely remained unexplored as a functional material. Despite the extraordinary stability and inertness of $\mathrm{CaC}_{2} \mathrm{O}_{4}$, for, e.g., coatings to protect marble and archeological monuments from environmental degradation, ${ }^{14} \mathrm{CaC}_{2} \mathrm{O}_{4}$ precipitation studies have remained limited to particles and bulk solids; applications for $2 \mathrm{D}$ nanomaterials have thus far not been exploited.

Received: March 11, 2019

Accepted: April 12, 2019

Published: April 12, 2019 


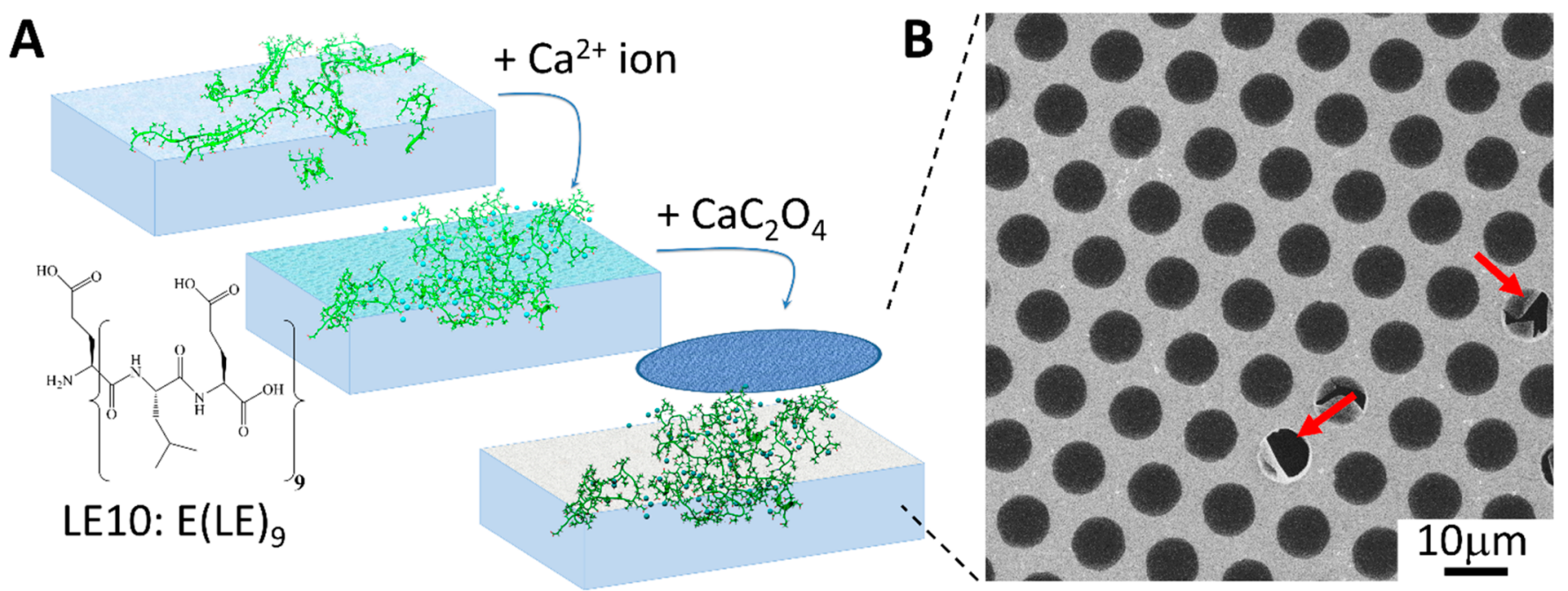

Figure 1. (A) LE10 peptide-mediated surface nucleation of $\mathrm{CaC}_{2} \mathrm{O}_{4}$ nanosheets. The sheets can be lifted off from the water surface with a TEM grid. (B) SEM image of a LE10 templated $\mathrm{CaC}_{2} \mathrm{O}_{4}$ sheet collected from the air-water interface using a TEM copper grid. Red arrows indicate the broken part of the sheet; defect-free sheets over $50 \times 50 \mu \mathrm{m}^{2}$ can routinely be achieved.

To investigate the potential of $\mathrm{CaC}_{2} \mathrm{O}_{4}$ biominerals as a $2 \mathrm{D}$ material, we report here the synthesis of $\mathrm{CaC}_{2} \mathrm{O}_{4}$ nanosheets at the air-water interface using biomimetic peptides (Figure 1A). Proteins that can effectively bind to a mineral surface are generally also effective nucleators of that mineral. Our choice of peptide for this experiment was inspired by the highly acidic human urinary protein osteopontin; it can specifically bind and passivate $\left(\mathrm{CaC}_{2} \mathrm{O}_{4}\right)$ kidney stones and thereby avoid the growth of larger stones. ${ }^{12,13}$ The peptide sequence $\mathrm{NH}_{2}-$ $\mathrm{E}(\mathrm{LE})_{9}-\mathrm{COOH}$ (abbreviated as LE10, Figure 1A) used in this study mimics the high glutamic acid content of osteopontin and has been shown to organize into strand-like structures at the air-water interface, ${ }^{10}$ reminiscent of binding sites in osteopontin. In a recent study, we found that $\beta$-folded leucine-glutamic acid (LE) peptides can effectively assemble vaterite calcium carbonate nanosheets by exploiting their structural flexibility at the air-water interface, ${ }^{10}$ which prompts us to explore this designed LE10 sequence to fabricate a novel 2D nanomaterial based on calcium oxalate.

Indeed, $\mathrm{CaC}_{2} \mathrm{O}_{4}$ nanosheets can be achieved by mineralizing $\mathrm{CaC}_{2} \mathrm{O}_{4}$ using the template of assembled LE10 peptides at the air-water interface. Figure $1 \mathrm{~A}$ illustrates the formation process of the $\mathrm{CaC}_{2} \mathrm{O}_{4}$ nanosheet: Firstly, the LE10 peptides were assembled at the air-water interface of a $20 \mathrm{~mL}$ trough filled with a $0.1 \mathrm{mg} / \mathrm{mL}$ solution of LE10 peptides. Upon surface adsorption, the subphase was diluted by a factor of 8 to reduce the bulk peptide concentration. Subsequently, calcium cations $\left(\mathrm{Ca}^{2+}\right)$ and oxalate anions $\left(\mathrm{C}_{2} \mathrm{O}_{4}{ }^{2-}\right)$ were injected into the subphase, this procedure led to $\mathrm{CaC}_{2} \mathrm{O}_{4}$ mineralization by LE10 peptides at the air-water interface. A thin layer of biomineral, consisting of mineral and peptides, could be lifted off of the interface with a transmission electron microscopy (TEM) grid. The scanning electron microscopy (SEM) image in Figure $1 \mathrm{~B}$ shows that the $\mathrm{CaC}_{2} \mathrm{O}_{4}$ sheet extends over the entire grid and is without visible cracks or fractures over an area of $50 \times 50 \mu \mathrm{m}^{2}$. The sheet is intact and freestanding over most of the grid holes where the film is without any support. The sheets shown in Figure 1B extend over several square millimeters across the TEM grid with comparable quality. It is challenging to retrieve the atomically resolved $\mathrm{CaC}_{2} \mathrm{O}_{4}$ crystal structure within the nanometer sheet from high-resolution
TEM measurement, in particular, taking into account the fact that the $\mathrm{CaC}_{2} \mathrm{O}_{4}$ crystals are typically decomposed into the amorphous phase by interaction with high-energy electrons. ${ }^{15}$ However, the observable diffuse rings from electron diffraction (Figure S3) suggests that the $\mathrm{CaC}_{2} \mathrm{O}_{4}$ crystals in the sheet are rather arranged into ordered nuclei prior to crystal growth, which is also in agreement with the nonclassic views of $\mathrm{CaC}_{2} \mathrm{O}_{4}$ mineralization. ${ }^{15}$

$\mathrm{X}$-ray photoelectron spectroscopy (XPS) analysis indicates that the nanosheets have a thickness of $\sim 2 \mathrm{~nm}$, and the elemental composition of the sheets (Table S1) reveals that each $\mathrm{Ca}^{2+}$ ion is shared by $\sim 2$ glutamic acid side chains of peptides. No contaminants or unexpected elements were detected within the sheets. The XP spectra (Figure S1) are in agreement with those of hybrid $\mathrm{CaC}_{2} \mathrm{O}_{4}$ /peptide sheets forming directly at the peptide interface. Combined, the SEM and XPS results clearly show that LE10 peptides grows $2 \mathrm{D} \mathrm{CaC}_{2} \mathrm{O}_{4}$ nanosheets.

To elucidate the molecular mechanism underlying $\mathrm{CaC}_{2} \mathrm{O}_{4}$ nanosheet formation, we applied surface-specific sum frequency generation (SFG) spectroscopy. SFG is a second-order nonlinear spectroscopy, sensitive to ordered species exclusively at the interface. ${ }^{16-19}$ This technique allows us to follow the molecular details of peptide arrangement, at the interface and in situ, during nanosheet formation. In our SFG measurement in the amide $\mathrm{I}$ region, $\mathrm{D}_{2} \mathrm{O}$ was used as the solvent instead of $\mathrm{H}_{2} \mathrm{O}$ to avoid spectral interference from $\mathrm{H}_{2} \mathrm{O}$ bending modes. Figure 2A shows SFG spectra using an SPS (S-polarized SFG, P-polarized vis, S-polarized IR) polarization combination for LE10 peptides assembled at the air-water interface, at different times after $\mathrm{Ca}^{2+}$ ion $\left(\mathrm{CaCl}_{2}\right)$ injection, and after $\mathrm{CaC}_{2} \mathrm{O}_{4}$ mineralization $\left(\mathrm{Na}_{2} \mathrm{C}_{2} \mathrm{O}_{4}\right.$ injection). The chosen SPS polarization combination is sensitive to both backbone and Glu side chain modes. ${ }^{10}$ The spectra of the pristine peptides exhibit two bands at $\sim 1576$ and $\sim 1612 \mathrm{~cm}^{-1}$, corresponding to the asymmetric $\mathrm{COO}^{-}$stretching vibration from the deprotonated Glu side chains ${ }^{20,21}$ and the B2 mode of the $\beta$ sheet backbone, respectively. ${ }^{22,23}$ The presence of two distinct bands indicates that both peptide backbone and side chains are well ordered at the buffer-air interface. Both bands increase in intensity upon $\mathrm{Ca}^{2+}$ ion interaction: the side chain band 


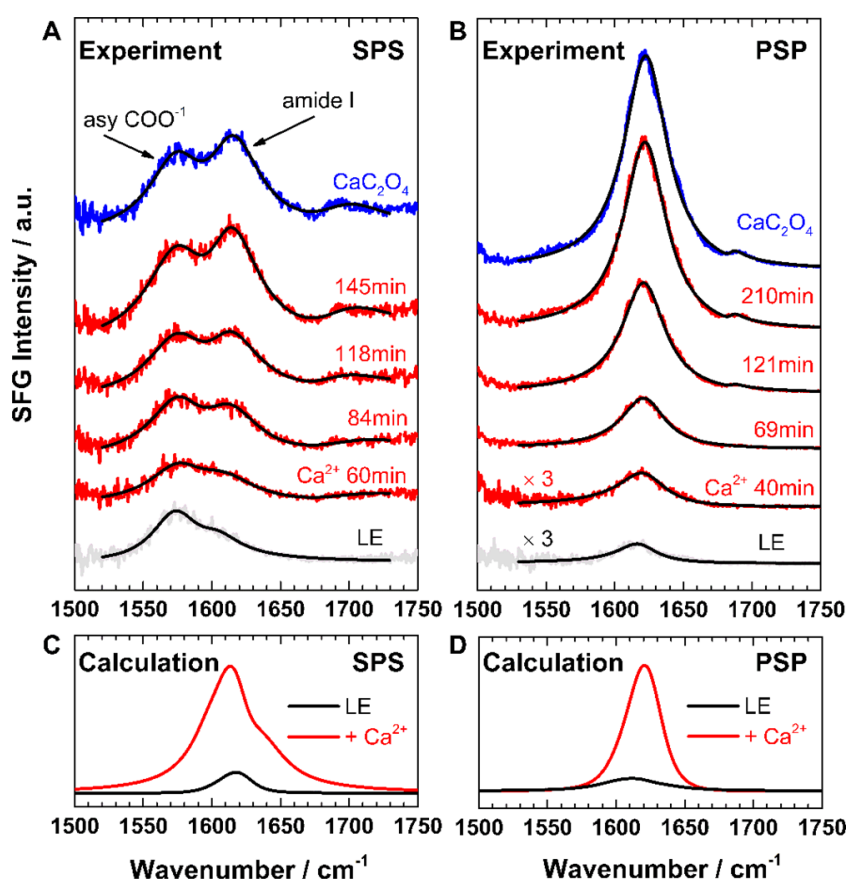

Figure 2. (A,B) Experimental SFG spectra in the amide I region for LE10 peptides at the air-water interface (gray), with $\mathrm{Ca}^{2+}$ ion interaction at different times after $\mathrm{CaCl}_{2}$ injection (red), and following $\mathrm{CaC}_{2} \mathrm{O}_{4}$ mineralization (blue). The spectra were acquired under (A) achiral SPS and (B) chiral PSP polarization combinations. The fits (black) are superimposed onto the experimental data. (C,D) Calculated amide I SFG spectra for peptides before and after $\mathrm{Ca}^{2+}$ ion interaction agree well with experimental spectra.

increases slightly, while the backbone amide I peak increases drastically, to saturate after $\sim 3 \mathrm{~h}$. The gradual amide I band increase indicates that the $\beta$-strands refold into more compact, ordered states. A weak feature at $\sim 1690 \mathrm{~cm}^{-1}$ appears after $\sim 2$ $\mathrm{h}$ of $\mathrm{Ca}^{2+}$ ion interaction; this high-frequency band can be assigned to $\beta$-turn motifs in less folded peptide aggregates. ${ }^{24} \mathrm{~A}$ detailed spectral analysis (Figure S6) reveals a slight frequency shift of the central amide I band from 1605 to $1612 \mathrm{~cm}^{-1}$ with time, possibly related to the couplings between the local modes of the turn motifs.

The backbone folding structure can be resolved in more detail using SFG spectra under chiral PSP polarization combinations (Figure $2 \mathrm{~B}$ ) that exclusively probe the amide bonds from $\beta$-folded peptides without spectral interference from achiral side chain modes. ${ }^{25,26}$ As expected, those spectra show only the predominant chiral amide I peak centered at $\sim 1620 \mathrm{~cm}^{-1}$, which originates from the $\beta$-sheet backbone, ${ }^{26}$ while the side chain band lacking chirality is fully suppressed. In accordance with the SPS spectra in Figure 2A, the interaction with $\mathrm{Ca}^{2+}$ ions enhances the amide I intensity and gives rise to a shoulder at $\sim 1690 \mathrm{~cm}^{-1}$, testifying to the peptide backbones refolding into more ordered, compact $\beta$ turns.

The SFG results provide direct experimental proof of peptide refolding upon interaction with $\mathrm{Ca}^{2+}$ ions-a key step for $\mathrm{CaC}_{2} \mathrm{O}_{4}$ sheet formation. For a molecular picture visualizing the critical assembled intermediate of peptides and $\mathrm{Ca}^{2+}$ ions, we performed molecular dynamics (MD) simulations for LE10 peptides in the absence and presence of $\mathrm{Ca}^{2+}$ ions. Snapshots in Figure 3A show the strand-like assembly of LE10 in the absence of $\mathrm{Ca}^{2+}$ ions. This secondary structure is also expected based on folding of the analogue positively charged leucine-lysine (LK) peptides at interfaces. ${ }^{27}$ For one unbiased result, $\mathrm{Ca}$ ions were randomly placed into the simulation box, with the initial snapshots shown in Figure S8. After simulation, $\mathrm{Ca}^{2+}$ ions were highly coordinated into interfacial peptides due to their strong interaction. A closer look (inset in Figure 3B) shows that each $\mathrm{Ca}^{2+}$ ion was chelated by two glutamic acid sites, which is in good agreement with the Calcium complexation ratio within the $\mathrm{CaC}_{2} \mathrm{O}_{4}$ sheet as determined from our XPS analysis. Here, the chelated $\mathrm{Ca}^{2+}$ ions, acting as the salt bridge, drive the backbones to "curl" and fold back on themselves, leading to more turn-like secondary structures, which is in agreement with our SFG band assignment.

We calculated theoretical SFG spectra of the amide I band over 200 frames from 100 to $500 \mathrm{~ns}$ in 2 ns steps for the four simulations, according to the formalism described in ref 28 (see the SI for more details). In calculations, the hydrogen bond-induced local-mode frequency shifts are modeled via the correlation found by Cho et al. among factors including the strength of the accepted and/or donated hydrogen bond(s), the $\mathrm{C}=\mathrm{O}$ length in the amide groups, and the local-mode amide I frequency. ${ }^{29}$ Specifically, we take the $\mathrm{C}=\mathrm{O}$ length from the coordinates and apply the equation $\nu=\nu_{0}+$ $\alpha \delta r_{\mathrm{CO}}$, where $\nu_{0}$ is the base frequency, $\alpha$ is the proportionality constant, and $\delta r_{\mathrm{CO}}$ is the deviation of the carbon-oxygen bond from its equilibrium value, which was $1.229 \AA$ for amide groups with secondary amines. The optimal match with the experimental spectra was found with $\alpha=1000$ and $\nu_{0}=$ $1622 \mathrm{~cm}^{-1}$. The calculated amide I spectra, as presented in Figure $2 \mathrm{C}, \mathrm{D}$, capture the band positions, spectral shape, and intensity increase observed for the amide I band in the experiments. The gradual appearance of a small band at $\sim 1690$ $\mathrm{cm}^{-1}$ in Figure 2A,B is not visible in the calculated spectra; this high-frequency mode is related to the aggregated $\beta$-turns from many peptide monomers, which can not be formed by the limited peptides as placed in the simulation box. However, the generally good agreement between calculation and experiment lends credence to simulation and prompted us to perform further analysis. Non-classical crystallization theories suggest that the $\mathrm{Ca}^{2+}$ ions coordinated by peptide side chains may template the $\mathrm{CaC}_{2} \mathrm{O}_{4}$ lattice and steer its growth within the sheet. ${ }^{15,30}$ We calculate the radial distribution function (RDF) of $\mathrm{Ca}^{2+}$ ions (Figure 3C), which shows a dominant peak near 4 A. Comparing this number with the calcium spacing within the Calcium oxalate mono- (COM) and dihydrate (COD) polymorphs, it becomes clear that, while the calcium spacing is smaller in COM, there is a remarkable match of the $\mathrm{Ca}^{2+}$ ion spacing within the peptide layer with the calcium spacing in COD. The MD simulations therefore suggest that LE10 peptides can effectively stabilize COD. Indeed, SEM images of the sheets collected after extended assembly times show the octahedral crystal shapes expected for COD (Figure S2). While $\mathrm{X}$-ray diffraction (XRD) measurements of the sheets have not yielded a diffraction signal, we have analyzed the crystal structure of $\mathrm{CaC}_{2} \mathrm{O}_{4}$ precipitated by $\mathrm{LE} 10$ in bulk solution. the XRD pattern further supports COD polymorph production by LE10 peptides (Figures S4 and S5).

In conclusion, using a facile approach, we have successfully fabricated $\mathrm{CaC}_{2} \mathrm{O}_{4}$ nanosheets by employing biomimetic $\beta$ sheet LE10 peptides assembled at the air-water interface. The obtained nanosheets are freestanding with defect-free areas exceeding $50 \times 50 \mu \mathrm{m}^{2}$. Combined SFG and molecular 


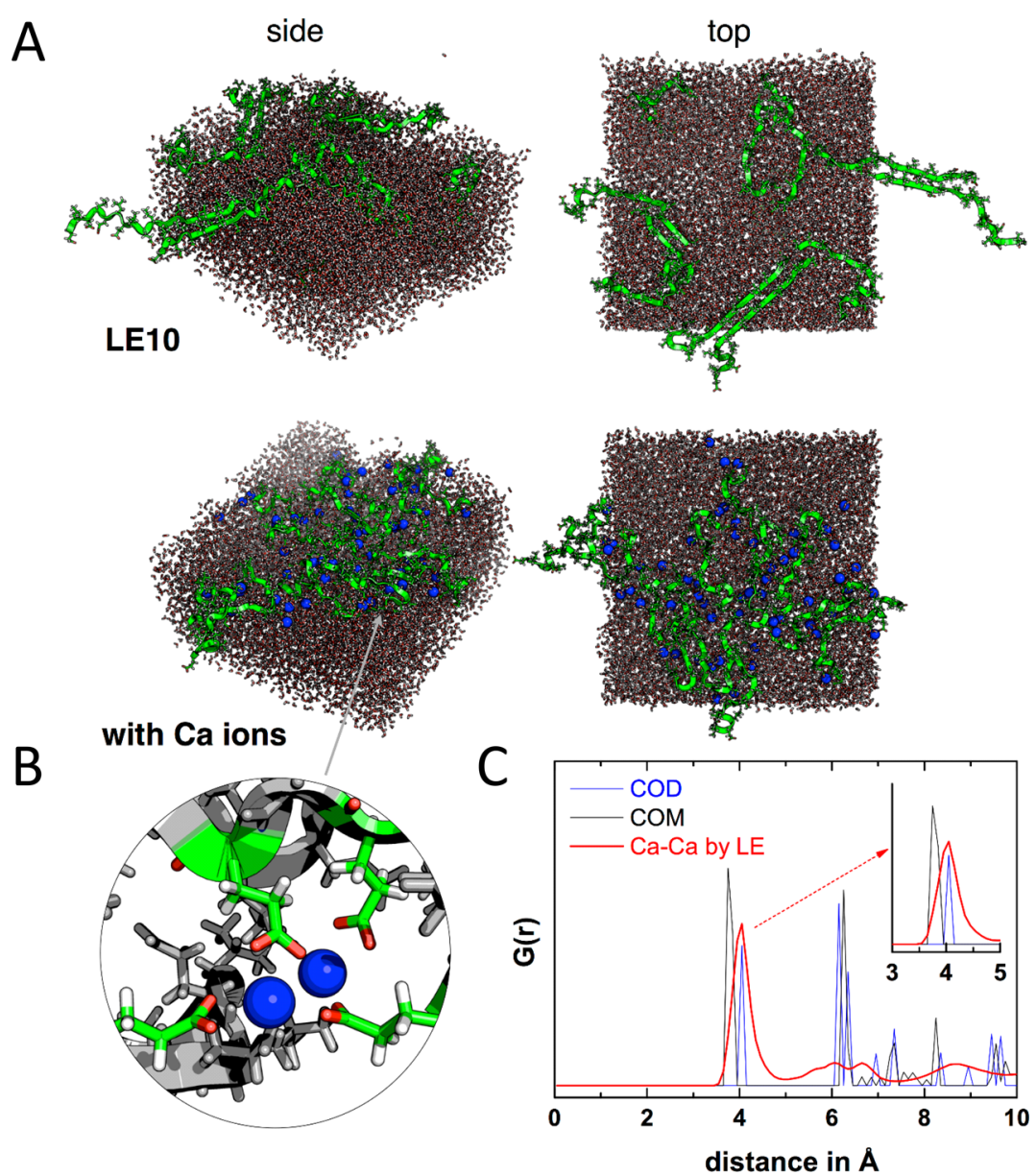

Figure 3. (A) Snapshots of MD simulations after $100 \mathrm{~ns}$ without and with $\mathrm{Ca}^{2+}$ ions. (B) Detailed view of glutamic acid side chains chelating Ca ions. Color scheme for rendered images: Ca ions, blue; peptide backbone, green; oxygen, red. (C) Radial distribution function $G(r)$ of the Ca-Ca distance within the simulations (red). $G\left(r_{\mathrm{Ca}-\mathrm{Ca}}\right)$ from crystal structure data for oxalate structures COM (black) and COD (blue) are also shown (see the main text for details).

dynamics simulation studies indicate that the nanosheet formation is enabled by the key interplay between peptides and $\mathrm{Ca}^{2+}$ ions: binding of the $\mathrm{Ca}^{2+}$ ions refines the peptide's structural motif, which in turn templates the $\mathrm{Ca}^{2+}$ ions to nucleate the $\mathrm{CaC}_{2} \mathrm{O}_{4}$ nanosheet by matching the $\mathrm{COD}$ lattice. The study shows that the inclusion of ion interactions in the design of functional peptides will be important for the design and fabrication of $2 \mathrm{D}$ inorganic biomimetic mineral nanosheets. This strategy could potentially be used to design mineral sheets using related templating molecules such as peptoids and block copolymers.

\section{ASSOCIATED CONTENT}

\section{S Supporting Information}

The Supporting Information is available free of charge on the ACS Publications website at DOI: 10.1021/acs.jpclett.9b00684.

Description of experimental procedures, more characterization on XRD, SEM, TEM, and XPS, description of SFG analysis and fitting parameters, description of $\mathrm{MD}$ simulations and SFG spectra calculation (PDF)

\section{AUTHOR INFORMATION}

\section{Corresponding Author}

*E-mail: lu@mpip-mainz.mpg.de.

\section{ORCID}

Hao Lu: 0000-0002-7338-2295

Helmut Lutz: 0000-0002-7915-8542

Steven J. Roeters: 0000-0003-3238-2181

Ingo Lieberwirth: 0000-0003-1323-524X

Rafael Muñoz-Espí: 0000-0002-8146-2332

Mischa Bonn: 0000-0001-6851-8453

Tobias Weidner: 0000-0002-7083-7004

\section{Notes}

The authors declare no competing financial interest.

\section{ACKNOWLEDGMENTS}

The authors greatly thank Elke Muth for the peptide synthesis and Michael Steiert for XRD measurements. SEM and TEM support by Gunnar Glasser and Katrin Kirchhoff is gratefully acknowledged. We gratefully acknowledge Helma Burg and Rüdiger Berger for AFM support. S.J.R. and T.W. are grateful for discussions about SFG spectra averaging with Dr. Sean A. Fischer. R.M.E. acknowledges financial support from the Spanish Ministry of Economy and Competitiveness through a Ramón y Cajal grant (Grant No. RYC-2013-13451) and from the Max Planck Society through funding of the Max Planck Partner Group on Colloidal Methods for Multifunctional Materials (CM3) at the University of Valencia. T.W. thanks the Deutsche Forschungsgemeinschaft (WE4478/4-1) 
and the Aarhus University Research Foundation (AUFF) for financial support.

\section{REFERENCES}

(1) Turchanin, A.; Golzhauser, A. Carbon Nanomembranes. Adv. Mater. 2016, 28, 6075-6103.

(2) Zhao, H. W.; Zhu, Y. J.; Li, F. S.; Hao, R.; Wang, S. X.; Guo, L. A Generalized Strategy for the Synthesis of Large-Size Ultrathin TwoDimensional Metal Oxide Nanosheets. Angew. Chem., Int. Ed. 2017, $56,8766-8770$.

(3) Mann, S. Biomineralization: Principles and Concepts in Bioinorganic Materials Chemistry; Oxford University Press: Oxford, 2001.

(4) Suzuki, M.; Saruwatari, K.; Kogure, T.; Yamamoto, Y.; Nishimura, T.; Kato, T.; Nagasawa, H. An Acidic Matrix Protein, Pif, Is a Key Macromolecule for Nacre Formation. Science 2009, 325, $1388-1390$

(5) Schrettl, S.; et al. Functional Carbon Nanosheets Prepared from Hexayne Amphiphile Monolayers at Room Temperature. Nat. Chem. 2014, 6, 468-476.

(6) Anselmetti, D.; Golzhauser, A. Converting Molecular Monolayers into Functional Membranes. Angew. Chem., Int. Ed. 2014, 53, 12300-12302.

(7) Robertson, E. J.; Battigelli, A.; Proulx, C.; Mannige, R. V.; Haxton, T. K.; Yun, L. S.; Whitelam, S.; Zuckermann, R. N. Design, Synthesis, Assembly, and Engineering of Peptoid Nanosheets. Acc. Chem. Res. 2016, 49, 379-389.

(8) Robertson, E. J.; Olivier, G. K.; Qian, M.; Proulx, C.; Zuckermann, R. N.; Richmond, G. L. Assembly and Molecular Order of Two-Dimensional Peptoid Nanosheets through the OilWater Interface. P. Natl. Acad. Sci. USA 2014, 111, 13284-13289.

(9) Qin, H. L.; Li, F. J.; Wang, D.; Lin, H. Z.; Jin, J. Organized Molecular Interface-Induced Noncrystallizable Polymer Ultrathin Nanosheets with Ordered Chain Alignment. ACS Nano 2016, 10, 948-956.

(10) Lu, H.; Lutz, H.; Roeters, S. J.; Hood, M. A.; Schafer, A.; Munoz-Espi, R.; Berger, R.; Bonn, M.; Weidner, T. Calcium-Induced Molecular Rearrangement of Peptide Folds Enables Biomineralization of Vaterite Calcium Carbonate. J. Am. Chem. Soc. 2018, 140, 27932796.

(11) Lutz, H.; Jaeger, V.; Schmüser, L.; Bonn, M.; Pfaendtner, J.; Weidner, T. The Structure of the Diatom Silaffin Peptide R5 within Freestanding Two-Dimensional Biosilica Sheets. Angew. Chem., Int. Ed. 2017, 56, 8277-8280.

(12) Qiu, S. R.; Wierzbicki, A.; Orme, C. A.; Cody, A. M.; Hoyer, J. R.; Nancollas, G. H.; Zepeda, S.; De Yoreo, J. J. Molecular Modulation of Calcium Oxalate Crystallization by Osteopontin and Citrate. Proc. Natl. Acad. Sci. U. S. A. 2004, 101, 1811-1815.

(13) Chien, Y. C.; Masica, D. L.; Gray, J. J.; Nguyen, S.; Vali, H.; Mckee, M. D. Modulation of Calcium Oxalate Dihydrate Growth by Selective Crystal-Face Binding of Phosphorylated Osteopontin and Polyaspartate Peptide Showing Occlusion by Sectoral (Compositional) Zoning. J. Biol. Chem. 2009, 284, 23491-23501.

(14) Delmonte, M.; Sabbioni, C.; Zappia, G. The Origin of Calcium Oxalates on Historical Buildings, Monuments and Natural Outcrops. Sci. Total Environ. 1987, 67, 17-39.

(15) Ruiz-Agudo, E.; Burgos-Cara, A.; Ruiz-Agudo, C.; IbanezVelasco, A.; Colfen, H.; Rodriguez-Navarro, C. A Non-Classical View on Calcium Oxalate Precipitation and the Role of Citrate. Nat. Commun. 2017, 8 (1-10), 768.

(16) Shen, Y. R. The Principles of Nonlinear Optics; J. Wiley: New York, 1984.

(17) Lambert, A. G.; Davies, P. B.; Neivandt, D. J. Implementing the Theory of Sum Frequency Generation Vibrational Spectroscopy: A Tutorial Review. Appl. Spectrosc. Rev. 2005, 40, 103-145.

(18) Roy, S.; Covert, P. A.; FitzGerald, W. R.; Hore, D. K. Biomolecular Structure at Solid-Liquid Interfaces as Revealed by Nonlinear Optical Spectroscopy. Chem. Rev. 2014, 114, 8388-8415.
(19) Ding, B.; Jasensky, J.; Li, Y.; Chen, Z. Engineering and Characterization of Peptides and Proteins at Surfaces and Interfaces: A Case Study in Surface-Sensitive Vibrational Spectroscopy. Acc. Chem. Res. 2016, 49, 1149-1157.

(20) Paszti, Z.; Guczi, L. Amino Acid Adsorption on Hydrophilic $\mathrm{TiO}_{2}$ : A Sum Frequency Generation Vibrational Spectroscopy Study. Vib. Spectrosc. 2009, 50, 48-56.

(21) Mudunkotuwa, I. A.; Minshid, A. A.; Grassian, V. H. ATRFTIR Spectroscopy as a Tool to Probe Surface Adsorption on Nanoparticles at the Liquid-Solid Interface in Environmentally and Biologically Relevant Media. Analyst 2014, 139, 870-881.

(22) Nguyen, K. T.; King, J. T.; Chen, Z. Orientation Determination of Interfacial Beta-Sheet Structures in Situ. J. Phys. Chem. B 2010, 114, $8291-8300$

(23) Singh, B. R. Infrared Analysis of Peptides and Proteins: Principles and Applications; American Chemical Society: Washington, DC, 2000.

(24) Hilario, J.; Kubelka, J.; Keiderling, T. A. Optical Spectroscopic Investigations of Model Beta-Sheet Hairpins in Aqueous Solution. J. Am. Chem. Soc. 2003, 125, 7562-7574.

(25) Fu, L.; Ma, G.; Yan, E. C. Y. In Situ Misfolding of Human Islet Amyloid Polypeptide at Interfaces Probed by Vibrational Sum Frequency Generation. J. Am. Chem. Soc. 2010, 132, 5405-5412.

(26) Fu, L.; Liu, J.; Yan, E. C. Y. Chiral Sum Frequency Generation Spectroscopy for Characterizing Protein Secondary Structures at Interfaces. J. Am. Chem. Soc. 2011, 133, 8094-8097.

(27) Baio, J. E.; Zane, A.; Jaeger, V.; Roehrich, A. M.; Lutz, H.; Pfaendtner, J.; Drobny, G. P.; Weidner, T. Diatom Mimics: Directing the Formation of Biosilica Nanoparticles by Controlled Folding of Lysine-Leucine Peptides. J. Am. Chem. Soc. 2014, 136, 15134-15137.

(28) Roeters, S. J.; van Dijk, C. N.; Torres-Knoop, A.; Backus, E. H. G.; Campen, R. K.; Bonn, M.; Woutersen, S. Determining in Situ Protein Conformation and Orientation from the Amide-I SumFrequency Generation Spectrum: Theory and Experiment. J. Phys. Chem. A 2013, 117, 6311-6322.

(29) Ham, S.; Kim, J. H.; Lee, H.; Cho, M. H. Correlation between Electronic and Molecular Structure Distortions and Vibrational Properties. II. Amide I Modes of NMA- $\mathrm{nD}_{2} \mathrm{O}$ Complexes. J. Chem. Phys. 2003, 118, 3491-3498.

(30) Gebauer, D.; Volkel, A.; Colfen, H. Stable Prenucleation Calcium Carbonate Clusters. Science 2008, 322, 1819-1822. 